\title{
Experimental Comparison of the
}

\section{Active Well Coincidence Counter with the Random Driver}

\section{MASTER}

䨌

¿

$\frac{2}{\omega}$

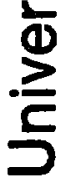

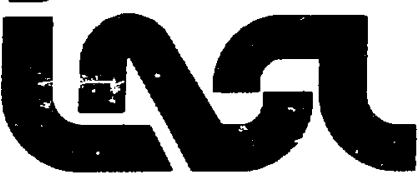


LA.7832-MS

Informal Report

UC.15

Issued. June 1979

\title{
Experimental Comparison of the
}

\section{Active Well Coincidence Counter with \\ the Random Driver}

\author{
Howard O. Menlove \\ Norbert Ensslin \\ Thomas E. Sampson
}

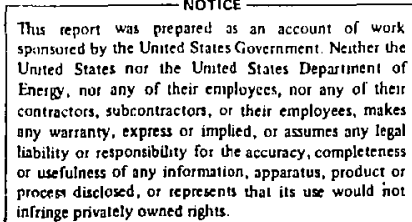

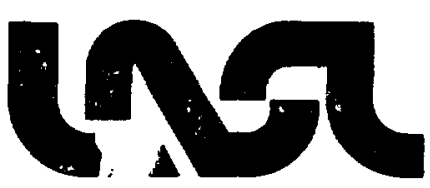




\section{CONTENTS}

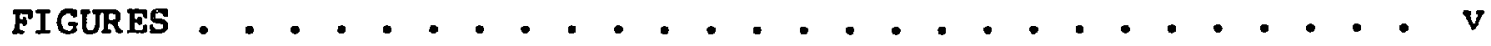

TABles ........................ . . . vi

ABSTRACT ........................ . 1

I. INTRODUCTION .................. I

II. RANDOM DRIVER DESCRIPTION . . . . . . . . . . . 2

III. ACTIVE WELL COINCIDENCE COUNTER . . . . . . . . . . 6

IV. EXPERIMENTAL PROCEDURES .............. 10

V. RESUlTS . . . . . . . . . . . . . . . . . . . . 11

A. $\mathrm{U}_{3} \mathrm{O}_{8}$-Large Containers . . . . . . . . . 11

1. Random Driver Results........... . 12

2. Active Well Coincidence Counter Results... . 14

B. HEU Metal Discs . . . . . . . . . . . 15

1. Random Driver Results . . . . . . . . . 17

2. Active Well Coincidence Counter Results . . . 18

3. Inhomogeneities . . . . . . . . . . . 20

c. Measurement precision and Stability . . . . . . 21

vi. Conclusions . . . . . . . . . . . . . . . . 22

A. Counting Rates . . . . . . . . . . . 22

B. Precision . . . . . . . . . . . . . 22

C. Penetrability and Linearity . . . . . . . . . . 22

D. Geometric iffects . . . . . . . . . . 23

E. Stability .................. 23

F. Matrix Iffects and Flux Monitors . . . . . . 23

G. Portability . . . . . . . . . . . . . 24 REFERENCES . . . . . . . . . . . . . . . . 25 


\section{FIGURES}

1. Random Driver (RD) counting chamber . . . . . . . . . . . . 4

2. Idealized timing distribution for Random Driver. Coincidence contributions are approximately to scale . . . 4

3. Normalized response vs height for the CMB-8 Random Driver . . . . . . . . . . . . . . . . . 5

4. Schematic diagram of Active Well Coincidence Counter (AWCC) in its normal configuration for counting small samples.... . . . . . . . . . . . . . 7

5. Vertical response profile for the AWCC showing the response from the individual sources and both sources combined (top curve) . . . . . . . . . . . . 8

6. Photograph of AWCC system copmplete with detector body and cart, electronics package and HP-97 calculator for automateó data readout and analysis . . . . . . 9

7. Photograph of $\mathrm{RD}$ system at CMB-3 including detector body, minicomputer, electronics rack and TSI terminal. . . 11

8. Random Driver response vs $g \mathrm{U}$ for highly enriched $\mathrm{U}_{3} \mathrm{O}_{8}$ powder and $\mathrm{U}_{3} \mathrm{O}_{8} \mathrm{mixed}$ with a graphite matrix (see Tables III and IV) .................. 13

9. AWCC response vs $g$ U for highly enriched $\mathrm{U}_{3} \mathrm{O}_{8}$ powder and $\mathrm{U}_{3} \mathrm{O}_{8} \mathrm{mixed}$ with graphite (see Tables III and IV) . . . . . . . . . . . . . . . . 15

10. Random Driver response vs $9 \mathrm{U}$ for HEU metal buttons (see Table VII) . . . . . . . . . . . . . 18

11. AWCC response vs $g \mathrm{U}$ for HEU metal buttons (see Table VII) ........................ . 19

12. Normalized response from the $\mathrm{RD}$ and $\mathrm{AWCC}$ for different configurations of two HEU metal discs combined with two depleted uranium metal discs 


\section{TABLES}

I. CONTRIBUTIONS OF VARIOUS COINCIDENCES FOR DIFFERENT COINCIDENCE GATES . . . . . . . . . . . 6

II. RD AND AWCC SYSTEM SPECIFICATIONS . . . . . . . 10

III. STANDARD SAMPLES OF PURE U308 . . . . . . . . . . . . . 12

IV. STANDARD SAMPLES OF U 308 PLUS GRAPHITE . . . . . . . . 12

V. RANDOM DRIVER MEASUREMENT RESULTS FOR U3O8 AND $\mathrm{U}_{3} \mathrm{O}_{8}$ PLUS GRAPHTTE STANDARDS ........... 14

VI. AWCC MEASUREMENT RESULTS FOR $\mathrm{U}_{3} \mathrm{O}_{8}$ AND $\mathrm{U}_{3} \mathrm{O}_{8}$

PLUS GRAPHITE STANDARDS .............. 16

VII. SPECIFICATIONS FOR HEU METAL DISCS . . . . . . . 16

VIII. HEU METAL BUTTONS MEASURED WITH THE RANDOM DRIVER . . 17

IX. HEU METAL BUTTONS MEASURED IN AWCC WITH Ni LINER IN WELL . . . . . . . . . . . . . . . . . . 19

X. STABILITY RESULTS FOR AWCC AND RD . . . . . . . . . 21 
EXPERIMENTAL COMPARISON OF THE ACTIVE WELL COINCIDENCE COUNTER WITH THE RANDOM DRIVER

by

Howard O. Menlove, Norbert Ensslin, and Thomas E. Sampson

\section{ABSTRACT}

A direct comparison has been made between the IAEA Active Well Coincidence Counter (AWCC) and the CMB-8 Random Driver. The comparison included an experimental evaluation of precision, counting rate, accuracy, penetrability, stability, and the effect of sample inhomogeneity.

Samples used in the evaluation included highly enriched $\mathrm{U}_{3} \mathrm{O}_{8}, \mathrm{U}_{3} \mathrm{O}_{8}$ mixed with graphite, highly enriched uranium metal discs, and depleted uranium metal. These materials are typical of the samples of interest to the IAEA inspectors.

We concluded from these investigations that the two instruments had very similar performance characteristics with the Random Driver giving better penetrability and the AWCC giving better stability.

\section{INTRODUCTION}

In recent years, random driver (RD) type instruments have been widely used for the nondestructive assay (NDA) of ${ }^{235} \mathrm{U}$. There have been several versions of random drivers ${ }^{1}$ - some designed and built by LASL and some by commercial instrumentation vendors. One of the commercial units was produced by National Nuclear Corp. for the International Atomic Energy Agency (IAEA). This unit (VERPACS) is currently used by the IAEA. The different RD units have generally improved over the years with better detectors, 
electronics, and data analysis techniques. However, this type of system is not readily adaptable to portable applications for field inspections because of its weight and complexity.

During this same period of time, neutron well coincidence counters have been successfully used for the passive assay o: plutonium. IAEA inspectors have found the portable high-level neutron coincidence counter (HLNCC) unit ${ }^{2}$ particularly useful for field applications. However, the instrument has not been applicable to the assay of ${ }^{235} \mathrm{U}$ or ${ }^{233} \mathrm{U}$ because of their extremely low spontaneous fission yields. To make this type of instrument applicable to the two uranium isotopes, we have used a combination of a small AmLi neutron interrogation source and a ${ }^{3}$ He thermal-neutron well coincidence counter. This Active Well Coincidence Counter $(A W C C)^{3}$ can be used for uranium samples, including high gamma-ray background materials such as ${ }^{233} \mathrm{U}-\mathrm{TH}$, fuels. The present AWCC was developed to be more lightweight and portable than the conventional fast random driver assay system.

The purpose of the present paper is to make a direct experimental comparison of the RD and the AWCC. The performance parameters of inierest in the comparison are:

1. counting rates,

2. precision,

3. stability,

4. response linearity, penetrability,

5. geometric effects,

6. sample inhomogeneities and matrix effects.

Samples that were available for the comparison included highly enrichei $\mathrm{U}_{3} \mathrm{O}_{8}$ in recovery cans, $\mathrm{U}_{3} \mathrm{O}_{8}$ mixed with graphite, and uranium metal discs $\left(93.158{ }^{235} \mathrm{U}\right)$ similar in size to the "buttons" and ingots used for fuel fabrication. The mass of the samples ranged from 250 to $4000 \mathrm{~g} \mathrm{U}$.

\section{RANDOM DRIVER DESCRIPTION}

The Random Driver is typically used to determine the enriched uranium content of oxide, metal, or residue samples. ${ }^{4}$ Typical container sizes are 5 to 10 liters capacity. AmLi random neutron 
sources are used to induce fisson reactions in the ${ }^{235} \mathrm{U}$ present in the material. Relatively few fissions occur in the ${ }^{238} \mathrm{U}$ because the neutron energy spectrum of the AmLi sources $10.3 \mathrm{MeV}$ average) is below the fission threshold for ${ }^{238} \mathrm{U}$. Also, the spontaneous fission rate of ${ }^{238} \mathrm{U}$ is very low. The fissions induced in ${ }^{235} \mathrm{U}$ are observed by coincidence counting the timecorrelated fission neutrons with two $5 \times 25 \times 50 \mathrm{~cm}$ Pilot F fast plastic scintillators, located on opposite sides of the assay chamber as shown in Fig. 1. By requiring the detection of neutrons in both scintillators within 45 nanoseconds, it is possible to distinguish fission events from randomly produced $A m L i$ source neutrons. The coincidence counting rate is proportional to the quantity of ${ }^{235} \mathrm{U}$ in the material being assayed, and thus provides a measure of the uranium content.

A number of features are incorporated in the design of the RD to reduce potential sources of assay bias. The interrogating neutrons are not thermalized, and the assay chamber is lined with boral to absorb low-energy neutrons, thus ensuring good neutron penetrability through the sample. The detectors are also shielded with $5 \mathrm{~cm}$ of lead, because the fast plastic scintillators are sensitive to energetic gamma rays as well as neutrons. This lead eliminates the gamma rays from the AmLi source and some of the induced fission gamma rays from ${ }^{235} \mathrm{U}$. Fission gamma rays are emitted with a multiplicity $v$ of $6-7$ (compared to 2.5 for the neutrons) and are typically $1-2 \mathrm{MeV}$ in energy. Since coincidence count rates are proportional to $v(v-1), 10$ times more soincidences will be produced by gammas than by neutrons. This feature can be used to increase detector count rate and sensitivity for small samples. However, the attenuation of gammas in most large samples is greater than the attenuation of neutrons. To make assays less dependent on sample density and composition, the RD discriminates against gamma rays by the use of lead and by timeof-flight. Gamma ray signa?s are detected in the scintillators in the first 2-3 ns, whereas neutron flight times are typically 20-40 ns, as illustrated in Jig. 2. A time window of 5-45 ns is used to accept luost $(n, n)$ coincidences and reject most $(Y, Y)$ 


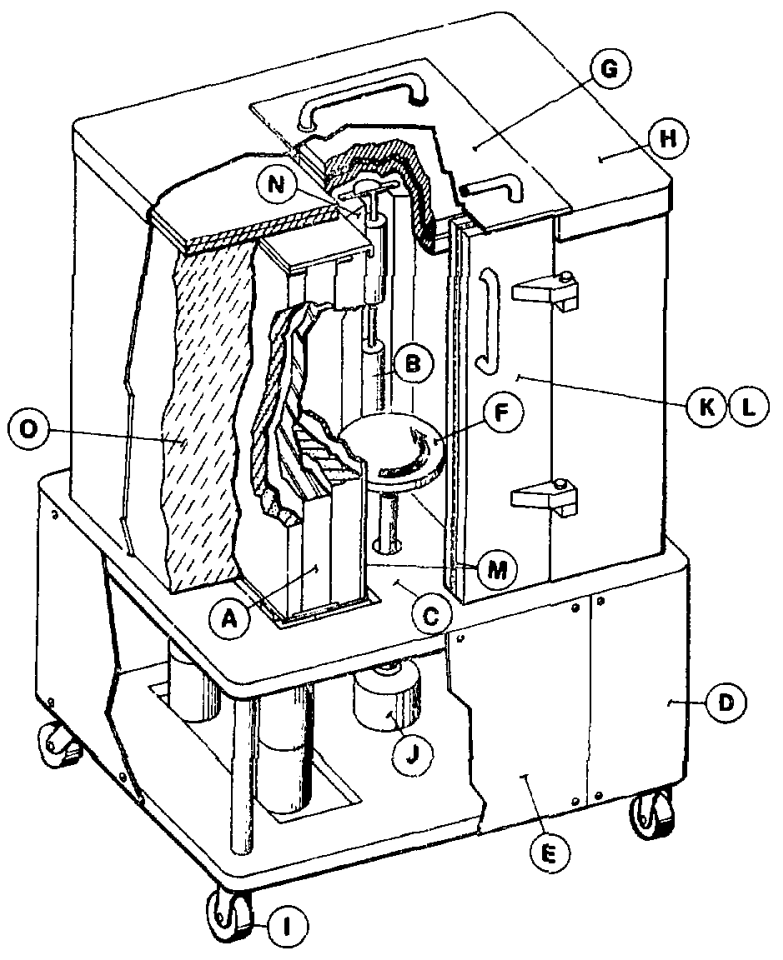

Fig. 1 .

Random Driver (RD) counting chamber - legend: A. scintillator assembiy, B. source, $C$. base, D. base skirting, E. front maintenance pane $1, F$. sample platen, G. I. d. H. top cover, I. casters, $J$. veighing mechanism, $K$. door, $L$. steel shielding, M. boral shielding, N. source tailoring concainer.
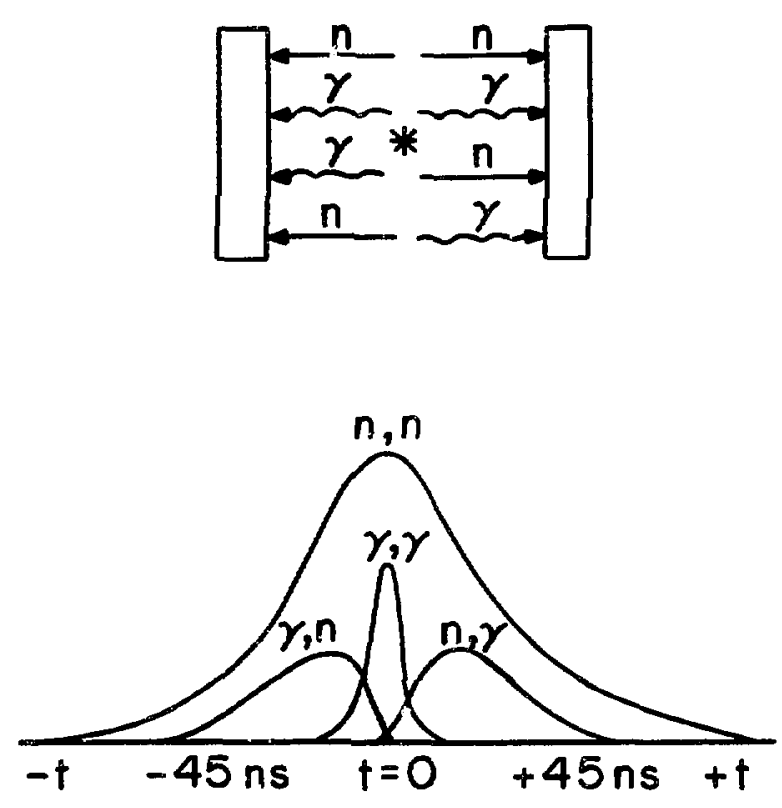

TIME DIFFERENCE
Idealized timing distribution for Random Driver. Coincidence contributions are approximately to scale.

coincidences. For typical energy threshold. of $650 \mathrm{keV}$ for neutrons and $220 \mathrm{keV}$ for gammas, the RD response consists of 788 $(n, n)$ coincidences and $22 \xi(n, \gamma)$ coincidences. 5 Táble I gives the contributions from neutron and gamma coincidences for the different time intervals.

Two techniques are used to reduce the effects of loading differences between samples. The sample is rotated during assay to minimize the effect of asymmetric loading of material within the container, and the AmLi sources are positioned to produce $a$ 
nearly uniform vertical response profile over the typical range of container fill heights $(2-20 \mathrm{~cm})$. Figure 3 illustrates the 3-58 variation in RD response as a function of height, as determined by moving a small sample along the central axis of the sample chamber. For large samples the total integrated response is constant to 18 or less over the range of fill heights. The distribution of neutron flux inside the sample is unknown and may vary more than 1\%. For this reason a correction for vertical response variation based on sample fill height is not made; however, the standards will normally have similar variations and the effect cancels out in the calibration curve.

The effect of introducing moderating material into the assay chamber is to reduce the energy of the interrogating spectrum, which increases the rate of induced fission in ${ }^{235} \mathrm{v}$. Light element moderating material can appear either as matrix or in polyethylene containers and bags. Because the type of container (i.e., metal or polyethylene) used for most materiai being

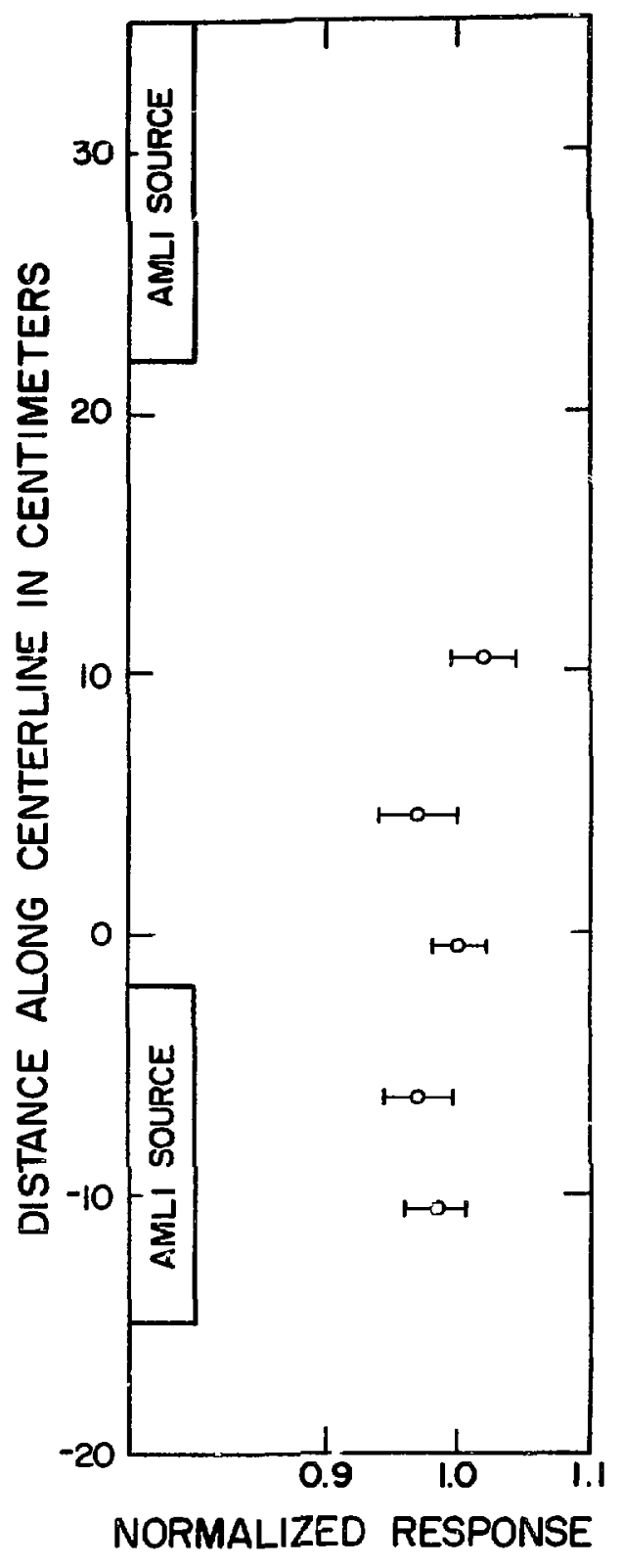

Fig. 3 .

Normalized response vs height for the CMB-8 Random Driver. 
assayed is dictated by the process stage in which the material occurs, assay data must be corrected for perturbations caused by moderat ing material in the sample chamber. This correction is based on the response of two $3_{\text {He proportional counters, }}$ located adjacent to the sample assay position, which monitor

TABLE I

CONTRIBUTTONS OF VARIOUS COINCIDENCES FOR DIFFERENT COINCIDENCE GATES

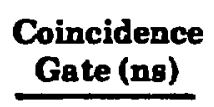

0 to 5

5 to 45

0 to 45

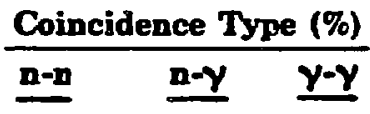

54

72

65

$\begin{array}{rr}21 & 25 \\ 25 & 0 \\ 25 & 10\end{array}$

the interrogating neutron flux.

The flux-monitor ratio, which

is the ratio of the ${ }^{3}$ He count rate with the sample in the chamber

to the ${ }^{3}$ He count rate with the chamber empty, provides a measure of the change in energy of the interrogating neutron spectrum. For routine applications, a correction factor based on the flux monitor ratio is automatically applied to the assay data by the RD computer. A similar empirical correction based on sample density is also applied to the assay data. This correction is presumably due to moderation, attenuation, and self-multiplication within the sample, but these effects have not been separated.

Elimination of some sources of assay bias by the instrument design features and corrections described above has reduced the number of physical standards required for calibration of the RD. However, experience with a wide variety of sample types has shown that widely different materials require different calibration curves to obtain good accuracy. The RD described in this report has separate calibration curves for pure uranium oxide, oxide mixed with graphite, uranium in hydrofluoric slag, and reduction metal residues.

III. ACTIVE WELL COINCIDENCE COUNTER

The basic principle of the AWCC is the same as the RD. That is, fast-neutron interrogation using a random neutron source (e.g., AmLi) and counting the induced fission reactions using coincidence techniques to suppress the signal from the random interrogation 
source. The primary difference is that the AWCC uses ${ }^{3}$ He detectors which are sensitive to neutrons after they have slowed. This necessitates the use of relatively long (32-64 us) coincidence time gates resulting in a large fraction of accidental coincidence events for high counting rates. To help alleviate this problem, we have positioned the $A m L i$ source inside $\mathrm{CH}_{2}$ shielding (the end plugs) as shown in Fig. 4 to reduce the accidental pileup rate. With this technique, the induced signal-to-interrogation neutron background ratio is improved by a factor of ten.

The AWCC has been designed to take advantage of the portable electronics package ${ }^{6}$ that was developed for the HiNCC. To keep this initial model as simple as possible and to take direct advantage of the previously developed electronics package, no neutron flux monitor has been incorporated into the present AWCC. Flux monitors are of ten used with active neutron assay inits to make corrections for neutron self-shielding or for neutron moderation in hydrogeneous matrix marerials. Operational experience with the present model will be used to evaluate the need for a flux monitor in more advanced models.

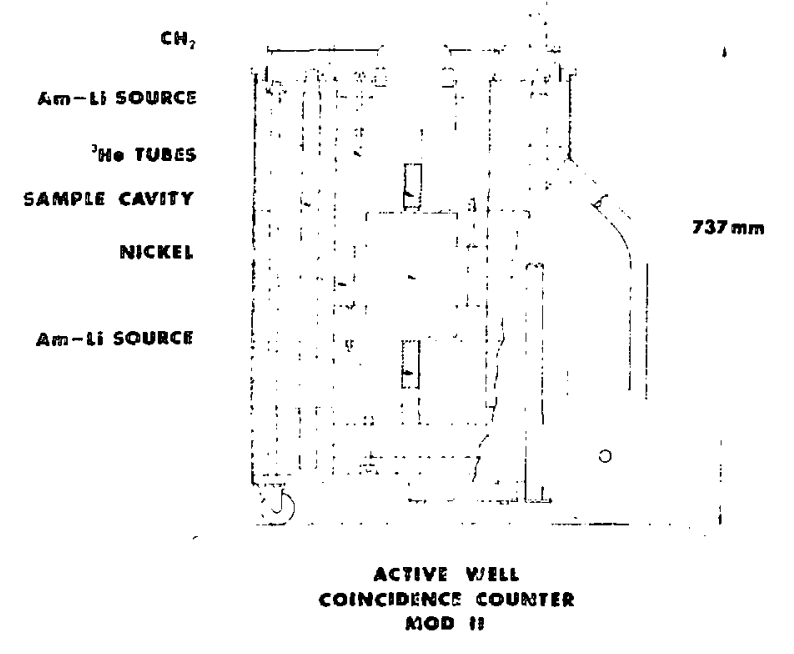

Fig. 4 .

Schematic diagram of Active Well Coincidence Counter (AWCC) in its normal configuration for counting small samples. 
Normally the sample cavity wall of the AWCC is lined with a 2.54-cm-thick nickel reflector to give a more penetrating neurron interrogation. However, the sample cans for the $\mathrm{U}_{3} \mathrm{O}_{8}$ plus graphite were so large $(20-\mathrm{cm}$ diam) that it was necessary to remove the nickel liner and the top and bottom $\mathrm{CH}_{2}$ discs $(7.6-\mathrm{cm}-\mathrm{th}$ ick) to accomodate the cans. The removal of the nickel results in some loss of penetrability. The counter was returned to the configuration shown in Fig. 4 for the measurements on the HEU metal discs.

A cadmium sleeve is placed on the outside of the detector to reduce the background rate from low energy neutrons in the room. There is also a sleeve of $\mathrm{Cd}$ in the detector well to remove thermal neutrons from the interrogation flux and to improve the shielding between the ${ }^{3} \mathrm{He}$ detectors and the AmLi source.

To obtain a more uniform spatial interrogation, two neutron sources of similar yield are used. One is in the lid and one is in the bottom plug as shown in Fig. 4. The use of two sources results in a rather uniform vertical response as shown in Fig. 5.

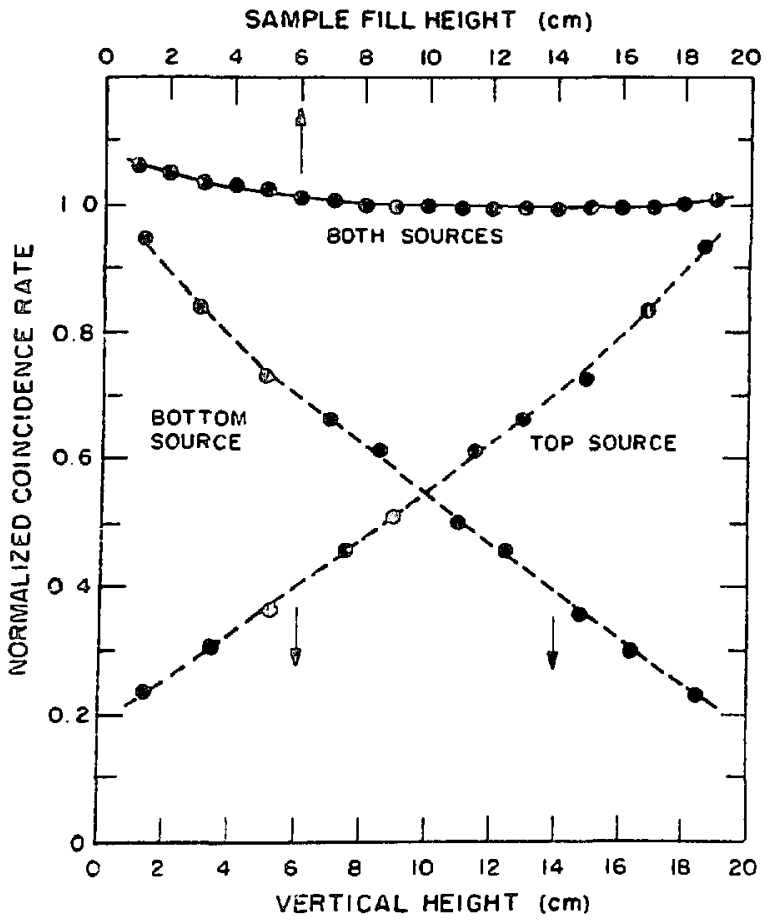

Fig. 5 .

Vertical response profile for the AWCC showing the response from the individual sources and both sources combined (top curve). 
The response is uniform $( \pm 28)$ for sample fill heights between 5 and $18 \mathrm{~cm}$. For a single source located in the bottom, the response changes by more than a factor of 4 over the same height range.

The unit use $32-^{3}$ He gas tubes that are $2.54 \mathrm{~cm}$ diameter and $50.8 \mathrm{~cm}$ long (active length). The $3_{\mathrm{He}}$ gas has $58 \mathrm{CO}_{2}$ added for improved gamma-ray insensitivity as compared to the normal additives. This detector configuration gives an absolute efficiency of $\sim 30 z$ for counting fission spectrum neutrons.

The electronics unit is directly interfaced to the HP-97 programmable calculator shown in Fig. 6. A microprocessor in the unit reads out the run time, total counts, reals plus accidental counts, and accidental counts to the HP-97. The HP-97 is then used to reduce the data using the software package selected by the operator.

Table II gives the specifications for both the RD and the AWCC showing the major physical differences in the two systems. The weight and size of the AWCC is considerably less than for the RD.

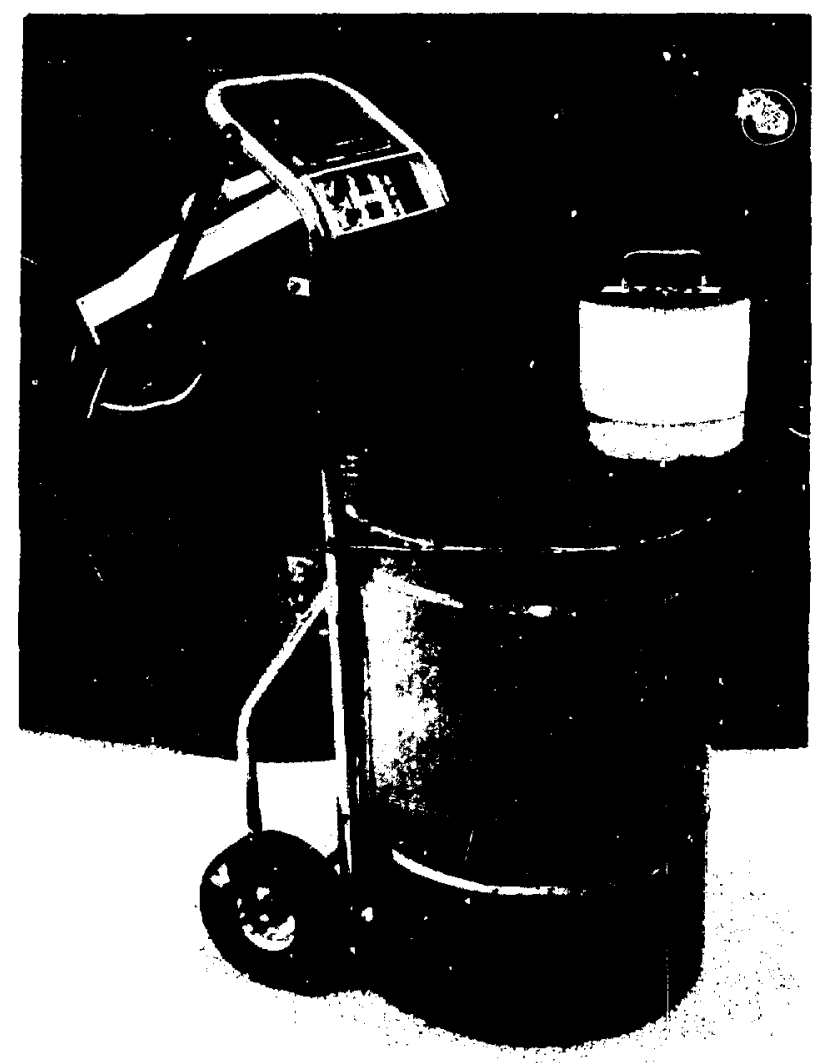

Fig. 6 .

Photograph of AWCC system complete with detector body and cart, electronics package and HP-97 calculator for automated data readout and analysis. 
RD AND AWCC SYSTEM SPECIFICATIONS

\begin{tabular}{|c|c|c|}
\hline & RD & AWCC \\
\hline Number of AmLi sources & 2 & 2 \\
\hline Total source strength & $106 \mathrm{n} / \mathrm{s}$ & $105 \mathrm{n} / \mathrm{s}$ \\
\hline Interrogation energy & Fast neutron & Fast neutron \\
\hline Detector type & Plastic scintillators & ${ }^{3} \mathrm{He}$ tubes \\
\hline Counting & $\begin{array}{c}\text { Fast neutrons and } \\
\text { gamma rays }\end{array}$ & $\begin{array}{r}\text { Thermalized } \\
\text { neutrons }\end{array}$ \\
\hline Response signal & Fast coincidence & $\begin{array}{l}\text { Slow coincidence } \\
\text { (autocorrelation) }\end{array}$ \\
\hline Coincidence gate & $\sim 45 \mathrm{~ns}$ & $\sim 64 \mu \mathrm{s}$ \\
\hline Body weight & $1150 \mathrm{~kg}$ & $125 \mathrm{~kg}$ \\
\hline Electronics & $\begin{array}{l}2 \text { NIM BINS plus } \\
\text { minicomputer }\end{array}$ & $\begin{array}{c}\text { HLNCC package } \\
\text { plus HP-97 }\end{array}$ \\
\hline
\end{tabular}

IV. EXPERIMENTAL PROCEDURES

For the comparison, the AWCC was taken to the uranium recovery plant at LASL, where the CMB-8 Random Driver shown in Fig. 7 is in routine use. Thus, both systems were operating side-by-side to obtain the same environmental factors. The samples were alternatively counted in the RD and the AWCC for the same time intervals typically $1000 \mathrm{~s}$. Repeat runs were performed on the lower mass samples to improve the counting statistics.

The samples selected for the measurement were those normaliy used for the calibration of the $R D\left(U_{3} O_{8}\right)$ olus the HEU metal discs that were prepared for IAEA detector calibration. Also, depleted uranium metal discs of the same size as the HEU discs were mixed with HEU discs to create inhomogeneities in the sample.

To check the stability of the systems, cyclic runs were performed over two nights and over a three day weekend. High mass samples were used for these runs to give good counting statistics to better check the precision. 
The primary evaluation considered the RD coincidence response directly without making corrections for the flux monitor or temperature sensor. This was to permit a direct comparison with the AWCC coincidence response which has no correction sensors in the present model. The data shown in the graphs and tables in section $V$ corresponds to the uncorrected response from both systems.

The magnitude of the correction factors for the $\mathrm{RD}$ were observed to be small and rather uniform over each of the sample categories. The effect of the correction factors is discussed in section VI.

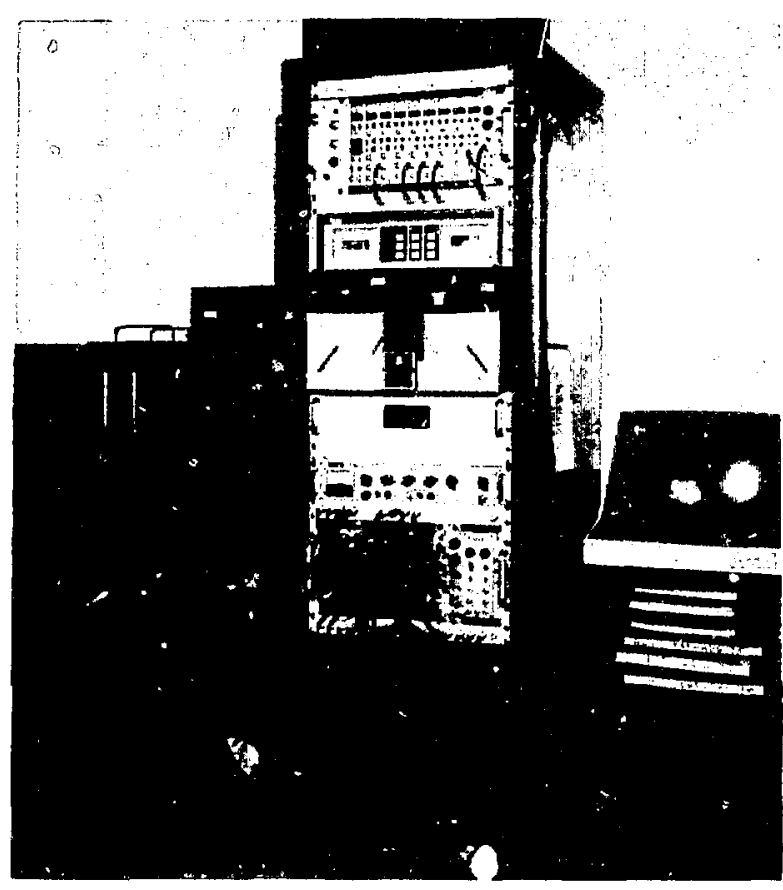

Fig. 7 .

Photograph of RD system at CMB-8 including detector body, minicomputer, electronics rack and TSI terminal.

\section{RESULTS}

\section{A. U ${ }_{3}{ }_{8}-$ Large Containers}

The RD located at the LASL uranium recovery facility is normally used to measure the ${ }^{235_{\mathrm{U}}}$ content of $\mathrm{U}_{3} \mathrm{O}_{8}$ in stainless steel cans that are $\sim 20-\mathrm{cm}-\mathrm{diam} \times 25 \mathrm{~cm}$ tall. This materiai is in two sample categories - each having its own set of standards. The first is pure $\mathrm{U}_{3} \mathrm{O}_{8}$ ranging in mass from 250 to $4000 \mathrm{~g}$ uranium ( 2938 enriched in ${ }^{235} \mathrm{U}$ ). The standards of this type material that were used for the comparison are 1 isted in Table III. The uranium is very concentrated and fills only the bottom few centimeters of the can resulting in a "pancake" shaped sample. The $\mathrm{U}_{3} \mathrm{O}_{8}$ had a density of approximately $2.38 \mathrm{~g} / \mathrm{cm}^{3}$ resulting in a ${ }^{335} \mathrm{U}$ density of $1.96 \mathrm{~g} / \mathrm{cm}^{3}$. This density was basically the same for all of the $\mathrm{U}_{3} \mathrm{O}_{8}$ standards with only the fill height changing as the sample mass increased. 
The set of $\mathrm{U}_{3} \mathrm{O}_{8}$ standards mixed with graphite are listed in Table IV. In this case the graphite fills most of the volume resulting in a low ${ }^{235} \mathrm{U}$ density. The mass of the uranium ranged from 234 to $4000 \mathrm{~g}$. The ${ }^{235} \mathrm{U}$ densities were 3 to 30 times lower than for the pure $\mathrm{U}_{3} \mathrm{O}_{8}$ material. Also, the densities and fill heights had large variations as given in Table IV. The large quantities of graphite in these containers had a significant effect on the observed signal for both assay systems.

1. Random Driver Results. The net coincidence response of the RD as a function of uranium content is shown in Fig. 8. All of the data points lie on a smooth curve which has the functional form aU/l+bu for uranium values less than $2000 \mathrm{~g}$. For the $4000 \mathrm{~g}$ sample, the multiplication gives a slight increase in the connidence response.

TABLE III

STANDARD SAMPLES OF PURE $\mathrm{U}_{3} \mathrm{O}_{8}$

\begin{tabular}{|c|c|c|c|c|c|c|}
\hline $\begin{array}{c}\text { Sample } \\
\text { ID } \\
\end{array}$ & $\begin{array}{l}\text { Net Wt. } \\
(\mathrm{g})\end{array}$ & $\begin{array}{l}\text { Fill Ht. } \\
(\mathrm{cm}) \\
\end{array}$ & $\begin{array}{l}\text { Diam } \\
\text { (cm) }\end{array}$ & gu & $\begin{array}{l}\text { Enr ichment } \\
(8)\end{array}$ & $\begin{array}{l}\rho^{235 U} \\
\left(\mathrm{~g} / \mathrm{cm}^{3}\right) \\
\end{array}$ \\
\hline $\begin{array}{l}\text { TRN- } 250 \\
\text { TRN- } 500 \\
\text { TRN- } 1000 \\
\text { TRN- } 1500 \\
\text { TRN- } 2000\end{array}$ & $\begin{array}{r}296 \\
591 \\
1183 \\
1774 \\
2366\end{array}$ & $\begin{array}{l}0.46 \\
0.91 \\
1.82 \\
2.73 \\
3.64\end{array}$ & $\begin{array}{l}18.2 \\
18.2 \\
18.2 \\
18.2 \\
18.2\end{array}$ & $\begin{array}{r}250 \\
500 \\
1000 \\
1500 \\
2000\end{array}$ & $\begin{array}{l}93.14 \\
93.14 \\
93.14 \\
93.14 \\
93.14\end{array}$ & $\begin{array}{l}1.94 \\
1.96 \\
1.96 \\
1.96 \\
1.96\end{array}$ \\
\hline
\end{tabular}

TABLE IV

STANDARD SAMPLES OF $\mathrm{U}_{3} \mathrm{O}_{8}$ PLUS GRAPHITE

\begin{tabular}{|c|c|c|c|c|c|c|}
\hline $\begin{array}{c}\text { Sample } \\
\text { ID } \\
\end{array}$ & $\begin{array}{l}\text { Net Wt. } \\
(\mathrm{g}) \\
\end{array}$ & $\begin{array}{l}\text { Fill Ht. } \\
(\mathrm{cm})\end{array}$ & $\begin{array}{l}\text { Di am } \\
(\mathrm{cm}) \\
\end{array}$ & $\mathrm{gU}$ & $\begin{array}{c}\text { Enr i chment } \\
(8) \\
\end{array}$ & $\begin{array}{l}\rho^{235 \mathrm{U}} \\
\left(\mathrm{g} / \mathrm{cril}^{3}\right)\end{array}$ \\
\hline STD- 234 & $\begin{array}{l}4678 \\
4678\end{array}$ & 13.5 & 20.0 & 234 & $\begin{array}{l}92.83 \\
92.83\end{array}$ & .0512 \\
\hline $\begin{array}{l}S T D-468 \\
\text { STD- } 500 \\
\text { STD-846 }\end{array}$ & $\begin{array}{l}40 / 0 \\
7005 \\
4230\end{array}$ & $\begin{array}{l}12.0 \\
19.3 \\
10.0\end{array}$ & $\begin{array}{l}20.0 \\
20.0 \\
20.0\end{array}$ & $\begin{array}{l}400 \\
500 \\
846\end{array}$ & $\begin{array}{l}92.03 \\
92.88 \\
92.83\end{array}$ & $\begin{array}{l}.0765 \\
.250\end{array}$ \\
\hline $\begin{array}{l}\text { STD-1000 } \\
\text { STD-1591 } \\
\text { STD- } 2000 \\
\text { STD- } 4000\end{array}$ & $\begin{array}{l}7335 \\
4679 \\
7640 \\
9691\end{array}$ & $\begin{array}{l}18.6 \\
12.5 \\
19.0 \\
18.0\end{array}$ & $\begin{array}{l}20.0 \\
20.0 \\
20.0 \\
20.3\end{array}$ & $\begin{array}{l}1000 \\
1591 \\
2000 \\
4000\end{array}$ & $\begin{array}{l}92.88 \\
92.83 \\
92.88 \\
92.88\end{array}$ & $\begin{array}{r}.159 \\
.376 \\
.311 \\
.657\end{array}$ \\
\hline
\end{tabular}




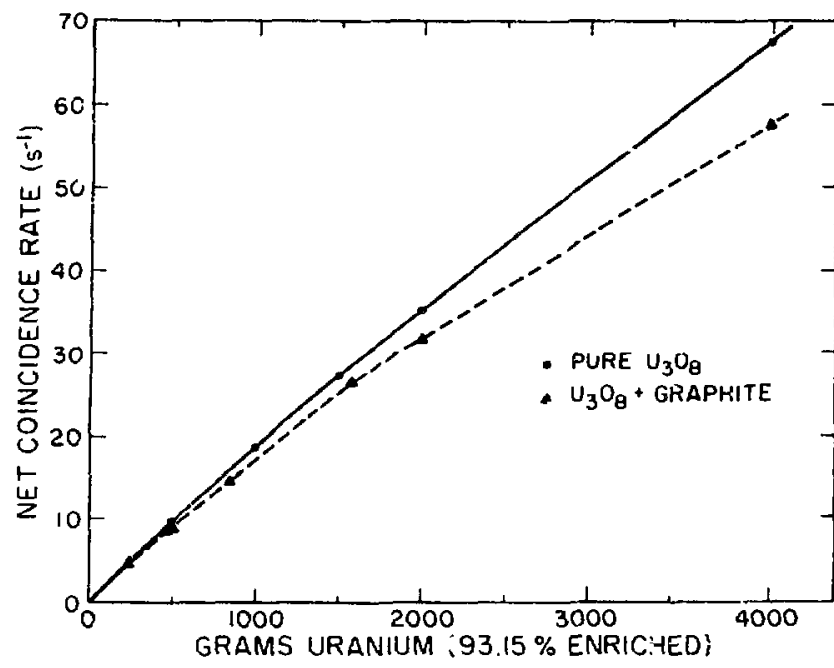

Fig. 8 .

Random Driver response vs $9 \mathrm{U}$
for highly enriched powder and $\mathrm{U}_{3} \mathrm{O}_{8} \mathrm{mixed}$ with a graphite matrix (see Tables III and IV).

The curve for the $U_{3} \mathrm{O}_{8}$ plus graphite Ealls below the curve for pure $\mathrm{U}_{3} \mathrm{O}_{8}$ for the $\mathrm{RD}$. This result is somewhat surprising because the graphite will increase the interrogation flux density and increase the number of slow neutrons which have a high fission cross section for ${ }^{235} \mathrm{U}$. Howeves . $\mathrm{r}$ the $\mathrm{RD}$, the graphite has the opposite effect on the counting charinel. That is, the induced fission neutrons and gamma rays have a more difficult time being counted by the plastic scintillators. The cans contain $4-6 \mathrm{~kg}$ of graphite which both absorbs fission gamma rays in transit to the scintillators and slows down the fast neutrons so that they are below the counting energy-threshold. This graphite has the opposite effect on the response for the AWCC which will be discussed in the next section.

The net coincidence response for the $\mathrm{U}_{3} \mathrm{O}_{8}$ samples are listed in Table $V$. The error corresponds to the calculated standard deviation for a $1000 \mathrm{~s}$ run. For the low mass samples, several measurements were performed to obtain better precision than the value listed in the table.

The last column in Table $V$ gives the coincidence rate per gram sample. This is an indication of the penetrability of the interrogation flux. A linear calibration curve would correspond to a constant value for the response per gram. The pure $\mathrm{U}_{3} \mathrm{O}_{8}$ curve is more linear than the graphite curve because the graphite moderates the interrogation neutrons resulting in more low-energy neutrons and thus more self-shielding in the ${ }^{235} \mathrm{U}$. 
TABLE V

RANDOM DRIVER MEASUREMENT RESULTS FOR U $\mathrm{U}_{3}$ AND $\mathrm{U}_{3} \mathrm{O}_{8}$ PLUS GRAPHI'TE STANDARDS

\begin{tabular}{|c|c|c|c|}
\hline $\begin{array}{c}\text { Sample } \\
\text { I.D.-g U }\end{array}$ & $\begin{array}{l}\text { Coincidence } \\
\text { Rate }\left(s^{-1}\right)\end{array}$ & $\begin{array}{l}\text { Standard } \\
\text { Deviation } \\
(1000 \mathrm{~s})\end{array}$ & $\frac{\text { Counts }}{\mathrm{s} \cdot \mathrm{gU}} \times 1000$ \\
\hline \multicolumn{4}{|l|}{$\mathrm{U}_{3} \mathrm{O}_{8}$} \\
\hline $\begin{array}{l}\text { TRN-250 } \\
\text { TRN-500 } \\
\text { TRN-1000 } \\
\text { TRN-1500 } \\
\text { TRN-2000 }\end{array}$ & $\begin{array}{l}4.90 \\
9.75 \\
18.7 \\
27.3 \\
35.3\end{array}$ & $\begin{array}{l}5.28 \\
2.08 \\
1.58 \\
1.18 \\
0.888\end{array}$ & $\begin{array}{l}19.6 \\
19.5 \\
18.8 \\
18.2 \\
17.6\end{array}$ \\
\hline \multicolumn{4}{|c|}{$\mathrm{U}_{3} \mathrm{O}_{8}$ plus Graphite } \\
\hline $\begin{array}{l}\text { STD- } 234 \\
\text { STD-468 } \\
\text { STD-500 } \\
\text { STD-846 } \\
\text { STD-1000 } \\
\text { STD-1591 } \\
\text { STD- } 2000 \\
\text { STD-4000 }\end{array}$ & $\begin{array}{l}4.27 \\
8.56 \\
8.84 \\
14.7 \\
16.8 \\
26.3 \\
31.5 \\
57.8\end{array}$ & $\begin{array}{l}5.88 \\
3.08 \\
2.98 \\
1.88 \\
1.68 \\
1.18 \\
0.988 \\
0.628\end{array}$ & $\begin{array}{l}18.3 \\
18.3 \\
17.7 \\
17.4 \\
16.8 \\
16.5 \\
15.8 \\
14.5\end{array}$ \\
\hline
\end{tabular}

2. Active Well Coincidence Counter Results. The results for the same set of standards measured with the AWCC are shown in Fig. 9. These curves are more nonlinear than the corresponding curves for the RD. This indicates a softer interrogation neutron spectrum for the AWCC. The reason for this is the large amount of hydrogen in the $\mathrm{CH}_{2}$ end plugs and detector walls.

The curve for the $\mathrm{U}_{3} \mathrm{O}_{8}$ plus graphite is above the $\mathrm{U}_{3} \mathrm{O}_{8}$ curve. We expect this to be the case because the large quantity of graphite increases the low energy neutron flux. As opposed to the RD, the graphite has little or no effect on the efficiency of the AWCC for counting the induced fission neutrons.

The data point at $1591 \mathrm{~g} U$ falls significantly below the curve through the other data points. A likely reason for the low response is that this can contains less graphite than the other cans with similar amounts of uranium resulting in less neutron moderation. Also, the graphite acts as a diluting agent for the $\mathrm{U}_{3} \mathrm{O}_{8}$ 


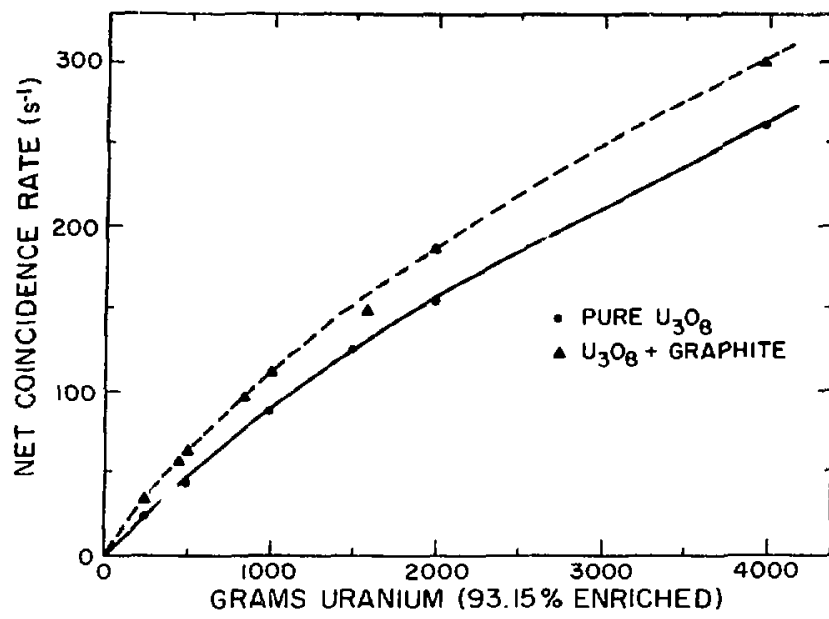

Fig. 9.

AWCC response vs $\mathrm{g} \mathrm{U}$ for highly enriched $\mathrm{U}_{3} \mathrm{O}_{8}$ piowder: and $\mathrm{U}_{3} \mathrm{O}_{8} \mathrm{mixed}$ with graphite (see Tables III and IV).

and less graphite means a higher concentration of $\mathrm{U}_{3} \mathrm{O}_{8}$ and thus more self-shielding. The AWCC is more sensitive to this type problem than the RD. The large sample cans made it necessary to remove the nickel liner from the AWCC and this increased the selfshielding problems.

The results of the AWCC measurements are listed in rable VI, and we see that the net coincidence rate for the AWCC is approximately 6 times higher than for the RD even though the AmLi source strength is a factor of ten smaller. The reason for this is the higher detector efficiency and the softer interrogation flux. It should be noted that the standard deviations for both the AWCC and RD are about the same in spite of this higher count rate. This is because of the high accidental coincidence rate in the AWCC contributing to the statistical error. The coincidence time gate in the AWCC is 64 us compared with about 45 ns for the RD.

B. HEU Metal Discs

The high enrichment metal discs used in the present experiment are similar to metal buttons or derbys of interest in inventory inspections. The samples included in the measuremerts are listed in Table VII. The two diameters $(6-$ and $7-\mathrm{cm})$ for the discs were used to check the effect of diameter variations in the measurements. 


\section{TABLE VI}

AWCC MEASUREMENT RESULTS FOR

$\mathrm{U}_{3} \mathrm{O}_{8}$ AND $\mathrm{U}_{3} \mathrm{O}_{8}$ PLUS GRAPHITE STANDARDS

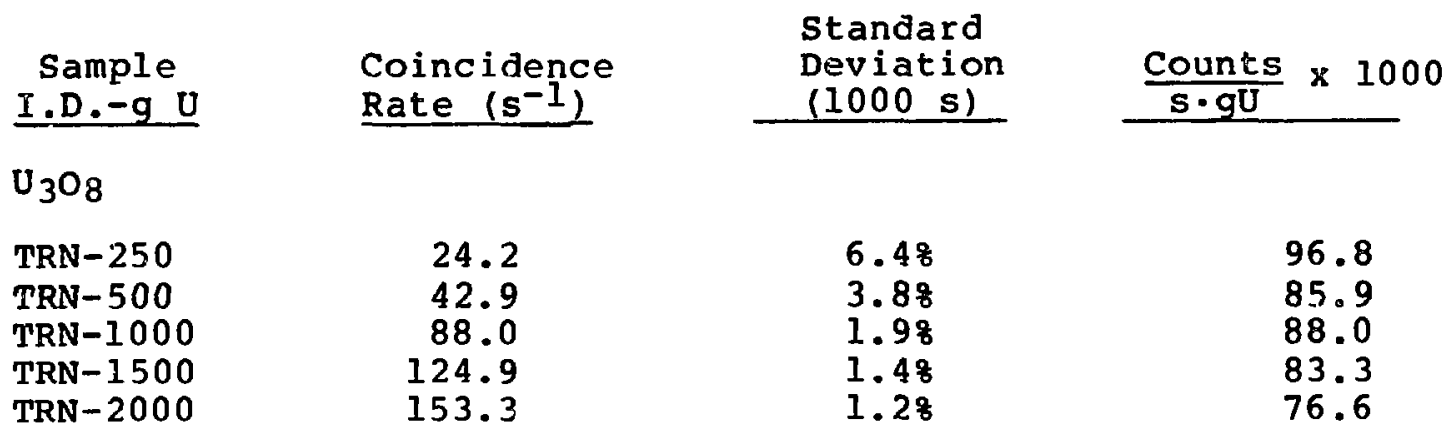

$\mathrm{U}_{308}$ Plus Graphite

$\begin{array}{lrcr}\text { STD-234 } & 33.4 & 5.18 & 142.6 \\ \text { S'ID-468 } & 56.0 & 3.18 & 119.7 \\ \text { STD-500 } & 61.9 & 2.88 & 123.8 \\ \text { STD-846 } & 96.6 & 1.98 & 114.2 \\ \text { STD-1000 } & 109.6 & 1.68 & 109.6 \\ \text { STD-1591 } & 147.3 & 1.28 & 92.6 \\ \text { STD-2000 } & 185.5 & 1.08 & 92.7 \\ \text { STD-4000 } & 300.2 & 0.618 & 75.0\end{array}$

TABLE VII

SPECIFICATIONS FOR HEU METAL DISCS

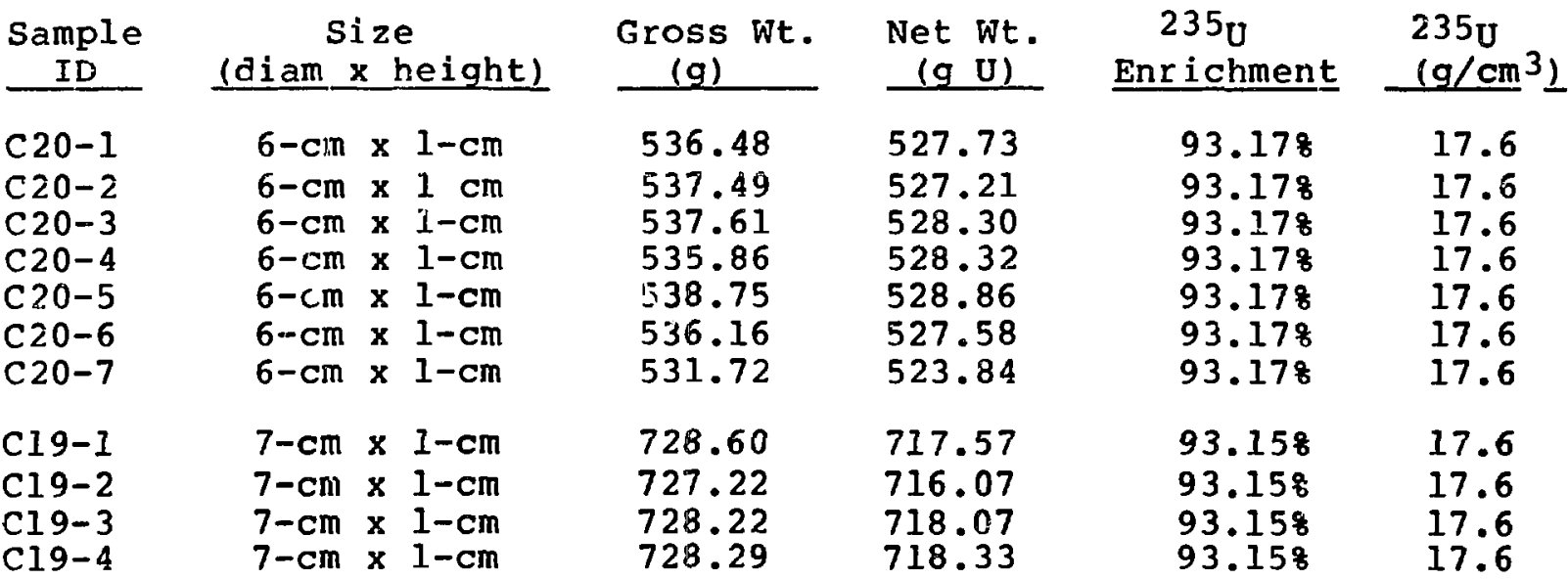


To obtain the mass range from approximately 500-4000 $\mathrm{g} \mathrm{U}$, the discs were stacked on top of each other to form a cylinder with heights varying from $1-\mathrm{cm}$ to $7-\mathrm{cm}$. The uranium metal had a density of $18.7 \mathrm{~g} / \mathrm{cm}^{3}$ resulting in a ${ }^{235} \mathrm{U}$ density of $17.5 \mathrm{~g} / \mathrm{cm}^{3}$. To avoid oxidation and contamination by the uranium, the discs were coated with a thin nickel plate.

1. Random Driver Results. The samples were counted in the RD with no change in the detector configuration used for the large $\mathrm{U}_{3} \mathrm{O}_{8}$ cans. The results of the measurements are given in Table VIII. The response per $g \mathrm{U}$ of a single disc (17.2) is somewhat less than the response per $g \mathrm{U}$ for the $U_{3} \mathrm{O}_{8}$ samples $(19.5$ for TRN-500). This reduction is likely caused by neutron or gamma self-shielding in the highe density metal.

As the sample mass increases from 1 disc to 7 discs, the response per gram increases from 17.2 to 20.7 or a 208 increase. This is caused by the multiplication of the induced fission neutrons.

TABLE VIII

HEU METAL BUTTONS MEASURED WITH THE RANDOM DRIVER

Sample size

diam $x$ ht. (cm)

$6 \times 1$

$6 \times 2$

$6 \times 3$

$6 \times 4$

$6 \times 5$

$6 \times 6$

$6 \times 7$

$7 \times 1$

$7 \times 2$

$7 \times 3$

784
Sample Massa Coincidence

9.10

528

1055

1583

2112

2640

3168

3692

718

1434

2152

2870
18.16

28.44

39.04

51.30

63.81

76.43

12.36

25.36

40.94

57.69
Standard

\begin{tabular}{l} 
Deviation \\
(1000 S run $)$ \\
\hline
\end{tabular}

4.28

$1.6 \%$

1.18

0.808

0.658

0.548

0.468

17.2

17.2

18.0

18.5

19.4

20.1

20.7

$2.16 \%$

1.158

0.788

0.608
17.2

17.7

19.0

a) Uranium metal samples 93.148 enriched in $235 \mathrm{U}$.

b) Corresponds to relative error in net coincidence rate considering only counting statistics. 
Figure 10 gives a plot of the net coincidence rate as a function of uranium mass. The curve is fit through the data for the 6-cm-diam discs. The larger 7-cm discs had an average response per gram that was only 1.68 higher than the smaller diameter discs.

The upward curvature of the response due to multiplication is evident. Techniques are under development to make automatic corrections in the data for multiplication.

2. Active Well Coincidence Counter Results. For the HEU

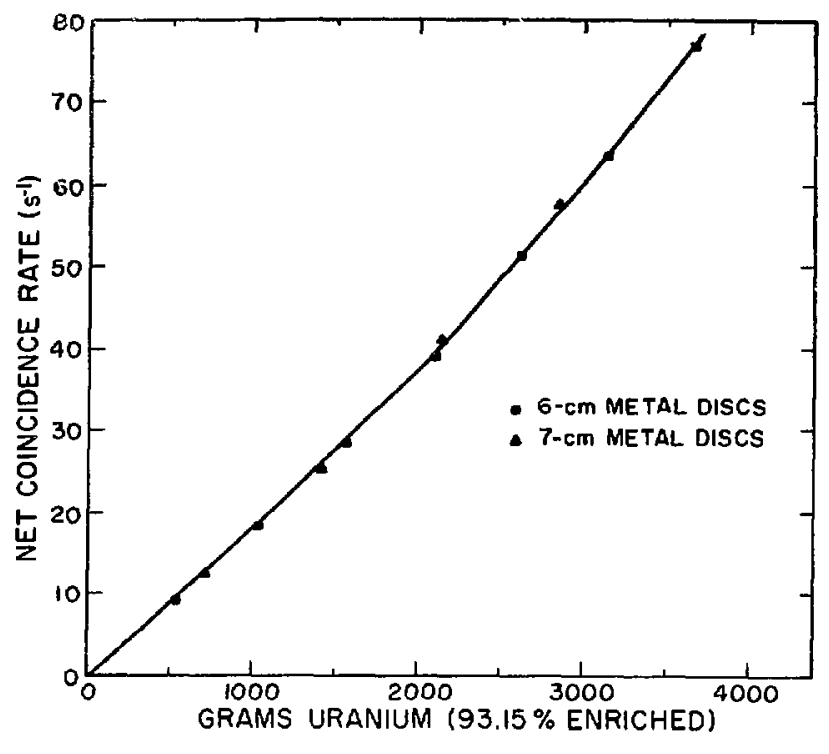

Fig. 10.

Random Driver response vs $g$ for HEU metal buttons (see Table VII). disc measurements, the AWCC was returned to its normal configuration as shown in Fig. 4. This smaller sample cavity increases the irradiation efficiency and the nickel liner improves the penetrability of the neutron flux.

Table IX gives the results for the different sample masses. The coincidence response per gram for a disc (87.2) is very close to the response for the $\mathrm{U}_{3} \mathrm{O}_{8}$ samples $(85.9$ for $\mathrm{TRN}-500)$; however, this is only a "coincidence" because the detector and end plug configuration was different for the two cases.

The response per gram changes by only 88 in going from 1 disc to 7 discs. There is a cancellation of self-shielding and multiplication effects. For the lower mass region $(<1500 \mathrm{~g} \mathrm{U})$ the self-shielding dominates resulting in a decline of the response per $g \mathrm{U}$, but for the higher mass values $(>2000 \mathrm{~g} \mathrm{U})$ the multiplicatin dominates resulting in an increase in the response per $g u$. The average difference in response per $g \mathrm{U}$ from the mean was only 2.78 . 
A plot of the coincidence rate versus the response is shown in Fig. 11. The curve is fit through the data points for the $6-\mathrm{cm}-$ diam discs. The $7-\mathrm{cm}$ discs fall sightly above the curve. The average rate per gram for the $7-\mathrm{cm}$ discs is $2.2 z$ higher than for the 6-cm discs.

\section{TABLE IX}

HEU METAL BUTTONS MEASURED IN AWCC WITH Ni LINER IN WELL

Sample Size

diam $x$ ht. (cm)

$6 \times 1$

$6 \times 2$

$6 \times 3$

$6 \times 4$

$6 \times 5$

$6 \times 6$

$6 \times 7$

$7 \times 1$

$7 \times 2$

$7 \times 3$

$7 \times 4$
Sample Massa (g U)

524

1055

1583

2111

2636

3164

3692

718

1434

2152

2870

\begin{tabular}{|c|}
\hline $\begin{array}{l}\text { Coincidence } \\
\text { Rate }\left(\mathrm{s}^{-1}\right.\end{array}$ \\
\hline $\begin{array}{c}45.72 \\
86.289 \\
127.55 \\
170.30 \\
218.73 \\
268.33 \\
318.33\end{array}$ \\
\hline $\begin{array}{r}66.22 \\
116.19 \\
179.11 \\
246.65\end{array}$ \\
\hline
\end{tabular}

\section{Standardb}

\begin{tabular}{l} 
Deviation \\
$(1000 \mathrm{~s}$ run $)$ \\
\hline
\end{tabular}

3.28

1.55

1.28

0.858

0.748

0.648

0.558

87.2

81.8

80.6

80.7

83.0

84.8

86.2

92.2

81.0

83.2

85.9

a) Uranium metal samples 93.178 enriched in ${ }^{235} \mathrm{u}$.

b) Corresponds to relative error in net coincidence rate considering only counting statistics.

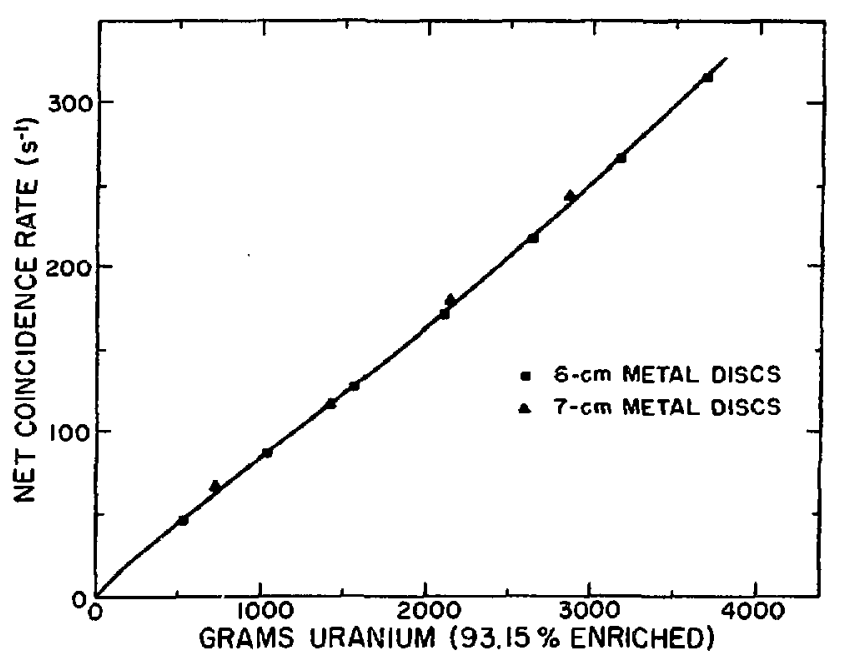

Fig. Il.

AWCC response vs $g$ f for HEU metal buttons (see Table VII). 
3. Inhomogeneities. A

pair of 6-cm-diam $x$ 1-cm-thick depleted uranium metal discs were used to check the sensitivity of the assay systems to inhomogenous samples. Two HEU metal discs were measured in the following configurations: a) two HEU discs with no depleted uranium (DU) discs, b) two HEU discs inside the DU discs, and c) two HEU discs outside the DU discs. The measurement configuration and the normalized coincidence rates are shown in Fig. 12 .

we see that the DU disc inhomogeneities change the results by only $\sim 28$ for the AWCC, but the change is $\sim 5 \%$ for
NORMALIZED COINCIDENCE RATE

RD AYCC

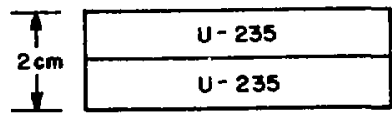

$1.000 \quad 1.000$

$0.948 \quad 0.985$

$0.945 \quad 0.98$ ।

Fig. 12 .

Normalized response from the RD and AWCC for different configurations of two HEU metal discs combined with two depleted uranium metal discs.

the RD. The RD has the larger perturbation because gamma rays contribute to its signal and he DU absorbs some of the gamma rays before they reach the scintillators.

Additional tests were performed where the $\mathrm{U}_{3} \mathrm{O}_{8}$ contents of sample TRN-2000 were forced to one side of the can. The measured rate was compared with the normal sample geometry. In this case the RD had less of a perturbation than the AWCC. This is partly because the $R D$ has a more penetrating interrogation flux than the AWCC and partly because there is less radial geometric variation in the $R \Gamma$. The sample rotates past the interrogation sources which averages out radial variations in the RD; whereas, there is no sample rotation in the AWCC, and the interrogation flux decreases with radial distance from the central axis of the well. 


\section{Measurement precision and Stability}

A series of measurements were performed overnight and over the weekend to check the precision and stability of the two systems. Normally the $1500 \mathrm{~g} \mathrm{U}$ or $2000 \mathrm{~g} \mathrm{U}$ samples were used in the counters to give the coincidence response.

The results of the measurements are given in Table $x$. The observed standard deviations are very close to the standard deviations predicted by counting statistics for the AwCC. The standard deviation in parentheses for the RD corresponds to the measured value after making corrections with the temperature sensor and the minicomputer. For cases with better statistical precision (e.g., the $10,000 \mathrm{~s}$ runs), the observed RD deviations are larger than would be expected from counting statistics alone. The cause of the instability is likely to be the scintillatorphoto tube system. The stability of the ${ }^{3}$ He detector system in the AWCC is very good.

TABLE $X$

STABILITY RESULTS FOR AWCC AND RD

Wednesday Overnight

(4000 s runs - $15 \mathrm{~h}$ period)

$1 \sigma$ predicted

lo observed

$\frac{\text { Net Coincidence Counts }}{\text { AWCC }}$

$0.55 \% \quad 0.428$

$0.598 \quad 0.828(0.548)$

Thursday Overnight

(4000 s runs - $15 \mathrm{~h}$ period)

$1 \sigma$ predicted

$1 \sigma$ óbserved

0.588

0.598

0.428

$0.45 \%(0.408)$

Friday - Monday

(10000 s runs - $60 \mathrm{~h}$ period)

$1 \sigma$ predicted

$1 \sigma$ observed

0.268

$0.28 \%$
C. $26 \%$

$1.04 \%(0.96 \%)$

a) The Io $_{0}$ value in parenthesis for the $\mathrm{RD}$ corresponds to the standard deviation of the coincidence count after making the temperature correction with the temperature sensor and minicomputer. 
VI. CONCLUSIONS

There are many characteristics and parameters to be considered in the comparison of the RD and AWCC systems. The relative importance of these parameters depends on the application and constraints on the user. A brief summary follows for the major parameters of interest.

\section{A. Counting Rates}

The net coincidence counting rate is $\sim 18 \times 10^{-3}$ counts/s $\mathrm{gU}^{\circ}$ for the $\mathrm{RD}$ and $\sim 84 \times 10^{-3}$ counts/sigu for the AwCC. However, this difference in rate is not important because the statistical error is dominated by the accidental coincidence rate which is considerably higher for the AWCC.

The fact that the AWCC uses AmLi sources that are an order of magnitude smaller than the $R D$ is important for portable applications.

\section{B. Precision}

The precision is linked to the net coincidence counting rate but it also includes the background rates and the electronic stabilities. The observed precision of the RD and the AWCC were essentially the same $(24-0.5 \%)$ for the counting intervals ( 1000 s) and mass range (500-4000 $\mathrm{g} U)$ of the present comparison. For higher masses or longer counting times, the statistical precision would drop below $\sim 0.5 \%$ and the AWCC would have some advantage because of its better stability.

other versions of random drivers that do not have the $\mathrm{Pb}$ shielding and jamma-ray time gate rejection, have a higher counting rate and better statistical precision. However, the penetrability/linearity is then worse and RD stability limits the observed precision in any case.

C. Penetrability and Linearity

Because of the large quantities of iron and lead close to the AmLi source and sample chamber, the RD has a harder neutron interrogation flux than the AWCC. This is demonstrated by the calibration curves for $\mathrm{U}_{3} \mathrm{O}_{8}$ where the linearity is better for the $\mathrm{RD}$ than the AWCC. The betier penetrability of the RD makes it possible to tolerate a larger variation in certain types of sample inhomogeneities. 


\section{Geometric Effects}

Changes in coincidence rates because of sample position variations or geometric effects were only briefly studied in the present work. The two source approach to flatten the spatial response is used in both instruments. The response variation as a function of fill height or vertical position is very small and essentially the same for both systems. The RD incorporates a rotating sample holder and side mounted neutron sources to reduce the effects of radial sample variations. The AWCC does not have this feature for two reasons. One is to keep the system simple from a mechanical standpoint, and the other is that the AmLi sources are mounted on the center axis of the AWCC to take advantage of the end plug shielding of the AmLi background neucrons.

Because of the above reasons and the larger sample cavity of the RD, that system is somewhat less subject to sample geometric effects.

\section{E. Stability}

One of the reasons for selecting ${ }^{3}$ He tubes for the AWCC was their excellent stability and their insensitivity to gamma rays. For high precision counting $(1 \sigma \leqslant 0.5-18)$ or applications with long periods between calibrations, the AWCC has better performance than the RD. The RD system uses plastic scintillator-phototube detectors which are subject to temperature variations and radiation fatigue. A temperature sensor is incorporated into the system and computer based corrections are made for these effects. F. Matrix Effects and Flux Monitors

The effects of matrix materials in the sample and the role of the fiux monitor were only lightly studied in the present comparison. This was because of the limited sample categories and the lack of a flux monitor in the AWCC.

The primary function of the ${ }^{3} \mathrm{He}$ flux monitor in the RD is to make corrections for hydrogen that might be present in the sample. Because there was no significant amount of hydrogen in the standards used in this comparison, the flux monitor correction was not large. However, if assay samples have moisture content or a 
large amount of plastic bagging material, a flux monitor might be required to indicate the problem and make appropriate corrections. The harder neutron interrogation spectrum of the RD makes it less sersitive to inhomogeneities that effect the interrogation neutrons such as self-shielding in lumps of fissile material. However, the AWCC is less sensitive to matrix materials that effect the counting of the induced fission reactions. Examples of this are density variations in the matrix materials which change the gamma-ray absorption and/or the fission neutron moderation as illustrated in Fig. 12.

In summary there is not a consistent advantage of one system over the other with respect to matrix effects. If the samples contain a significant amount of moisture, a flux monitor should be used, or if the fissile density is low, thermal-neutron interrogation can be used to override the hydrogen effect.

G. Portability

The relative portability of the two systems was only indirectly checked in the present work. That is, the AWCC was carried to the site of the RD rather than the other way around.

In all factors which pertain to portability, the AWCC is better. The key parameter is the weight and the AWCC is roughly a factor of ten lighter. The size of the AWCC electronics is about an order of magnitude smaller than $\mathrm{cor}$ the RD. However, the RD electronics could be reduced with sufficient effort. The AWCC is more rugged, stable, less complex, and less sensitive to temperature variations than the RD. Also, when the AWCC is turned on at a new location, the warmup time for the electronics is only a few minutes compared with several hours for the RD. The factor-of-ten smaller Am-Li source strength is another advantage of the AWCC with respect to transportation logistics.

In summary, the performance characteristics of the RD at CMB-8 and the AWCC are quite similar with respect to precision and sensitivity. The AWCC has many obvious advantages for portable applications as detailed above. For in-plant or fixed-site applications the $\mathrm{RD}$ has the advantage of better neutron penetrability. Also 
the minicomputer based data analysis system can be used for measurement control functions that are not possible with the smaller portable electronics. For samples with high gamma-ray backgrounds such as irradiated fast critical assembly plates and ${ }^{23} \mathrm{U}-\mathrm{Th}$ fuel materials, the AWCC has the advantage of being insensitive to the gamma-ray backgrounds.

IAEA inspector applications normally require equipment that can be easily moved from one site to another, and thus the AWCC more closely meets their need.

\section{REFERENCES}

1. T. L. Atwell, J. E. Foley, and L. V. East, "NDA of HTGR Fuel Using the Random Driver," Journal of the Institute of Nuclear Materials Management, Vol. III, No. III, pp. 171-188 (1974).

2. Merlyn Stewart Krick and Howard 0 . Menlove, "The High-Level Neutron Coincidence Counter (HLNCC): Users' Manual," Los Alamos Scientific Laboratory report LA-7779-M (1978).

3. Howard 0 . Menlove, "Description and Operation Manual for the Active Well Coincidence Counter," Los Alamos Scientific Laboratory report LA-7823-M (1979).

4. D. Langner, T. L. Atwell, T. R. Canada, N. Ensslin, L. Cowder, T. Van Lyssel, and H. R. Baxman, "The CMB-8 Material Balance System Measurement Controi Program," Los Alamos Scienific Laboratory report (1979).

5. D. M. Lee, N. Ensslin, C. Shonrock, and T. Van Lyssel, "Random Driver Studies," Los Alamos Scientific Laboratory report LA-7211-PR, Sept.-Dec. 1977, p. 14.

6. J. E. Swansen, N. Ensslin, M. S. Krick, and H. O. Menlove, "A New Shift Register for High Count Rate Coincidence Applications," LOS Alamos Scientific Laboratory report LA-6788-PR (1977) pp. 4-6. 